\title{
Tinjauan Akurasi Kode Diagnosis Dan Kode Penyebab luar Pada Kasus Cedera Kepala Yang Disebabkan Kecelakaan Lalu Lintas Di Rumah Sakit Umum Pusat
}

\section{The accuracy of the diagnosis code and external code cause head injury cases caused by traffic accidents in Central General Hospital}

\author{
Arief Tarmansyah Iman') \\ Maulana Yusuf Ismail2) \\ Dedi Setiadi ${ }^{3}$ )
}

\author{
Program Studi DIII Perekam dan Informasi Kesehatan, Poltekkes Kemenkes \\ Tasikmalaya, Jalan Cilolohan No. 35, Kota Tasikmalaya \\ arief.tarmansyah@dosen.poltekkestasikmalaya.ac.id
}

\begin{abstract}
According to the RISKESDAS 2018, the number of injuries in West Java Province is the largest in Indonesia, with 16,150 cases and 5,184 occurring on the highway. Based on the preliminary study, of the 10 medical record documents the accuracy rate is $20 \%$. The purpose of this study was to determine the accuracy of the diagnosis code and external cause in head injury cases caused by traffic accidents in Central General Hospital. Research Methodology is Quantitative Descriptive, population 145 medical record documents head injury cases caused by traffic accidents in 2018, a total sample of 106. The sampling technique was simple random sampling. Data collected was done by observation and Data analysis used univariate analysis. The accuracy of the diagnosis code was $66.1 \%$ accurate and $33.9 \%$ was inaccurate. Accuracy of external cause code is $67.9 \%$ accurate and $32.1 \%$ is inaccurate. The inaccuracy of the diagnosis code is caused by three characters, which is $2.8 \%$, the fourth character is $20.7 \%$ and the fifth character is $51.9 \%$. The inaccuracy of the external cause code caused by three characters is $30.2 \%$, the fourth character is $34.0 \%$ and the fifth character is $37.7 \%$. So it conclude that the accuracy of the diagnosis code and external code cause head injury cases caused by traffic accidents are mostly inaccurate. Inaccuracies in the diagnosis code and external cause code are mostly caused by the fifth character.
\end{abstract}

Keywords: ICD-10, head injury, traffic accident

\begin{abstract}
Abstrak
Menurut RISKESDAS 2018, kasus cedera di Provinsi Jawa Barat merupakan yang terbanyak di seluruh Indonesia sebanyak 16.150 kasus dan 5.184 terjadi di jalan raya. Berdasarkan studi pendahuluan, dari 10 dokumen rekam medis cedera kepala tingkat akurasinya adalah $20 \%$. Tujuan penelitian ini untuk mengetahui akurasi kode diagnosis dan kode penyebab luar pada kasus cedera kepala yang disebabkan kecelakaan lalu lintas di Rumah Sakit Umum Pusat dr. Hasan Sadikin Bandung. Metodologi Penelitian ini kuantitatif deskriptif, populasi 145 dokumen rekam medis kasus cedera kepala yang disebabkan kecelakaan lalu lintas tahun 2018, total sampel 106. Teknik pengambilan sampel adalah simple random sampling. Cara pengumpulan data dilakukan dengan observasi. Analisis data yang digunakan analisis univariat. Akurasi kode diagnosis sebesar $66,1 \%$ akurat dan 33,9\% tidak akurat. Akurasi Kode penyebab luar sebesar $\quad 67,9 \%$ akurat dan 32,1 \% tidak akurat. Ketidakakuratan kode diagnosis disebabkan pada tiga karakter yaitu sebesar 2,8 \%, karakter keempat sebesar $20,7 \%$ dan karakter kelima sebesar $51,9 \%$. Ketidakakuratan kode penyebab luar yang
\end{abstract}


disebabkan tiga karakter sebesar 30,2 \%, karakter keempat 34,0 \% dan karakter kelima sebesar $37,7 \%$. Akurasi kode diagnosis dan kode penyebab luar kasus cedera kepala yang disebabkan oleh kecelakaan lalu lintas sebagian besar tidak akurat. ketidakakuratan kode diagnosis dan kode penyebab luar sebagian besar disebabkan oleh karakter kelima.

Kata Kunci: cedera kepala, ICD-10, kecelakaan lalu lintas

\section{Pendahuluan}

Dewasa ini, pelayanan kesehatan merupakan satu hal yang tidak bisa dipisahkan dari kebutuhan masyarakat. Kebutuhan yang tinggi akan pelayanan kesehatan ini membuat sarana pelayanan kesehatan lebih memaksimalkan semua aspek dalam hal pelayanan. Salah satu hal yang penting dalam pelayanan kesehatan adalah pertolongan pertama saat terjadi kasus kecelakaan lalu lintas yang menyebabkan cedera. Dari tahun ke tahun, jumlah kendaraan di Indonesia semakin bertambah. Hal ini bisa menjadi acuan sarana pelayanan kesehatan untuk menyiapkan pelayanan kesehatan yang maksimal saat terjadi kondisi gawat darurat akibat kecelakaan lalu lintas. Berdasarkan hasil RISKESDAS 2018, cedera di bagian kepala Provinsi Jawa Barat memiliki proporsi sebesar 12,3\% atau 1.986 dari 16.150 kasus. Menurut tempat kejadiannya, kasus cedera di Jawa Barat di jalan raya menempati urutan kedua dengan proporsi $32,1 \%$ atau 5.184 dari 16.150 kasus. Cedera yang disebabkan oleh kecelakaan di Provinsi Jawa Barat sendiri memiliki proporsi sebesar $2,2 \%$ atau 4.110 dari 186.809.

Seiring dengan tingginya angka cedera kepala dan kecelakaan lalu lintas di Indonesia maka pendokumentasian yang baik dan benar mengenai kasus cedera kepala dan kecelakaan lalu lintas akan sangat berguna bagi RSUP dr. Hasan Sadikin Bandung dalam menentukan kebijakan dalam pengobatan dan perawatan pasien cedera kepala dan kecelakaan lalu lintas.
Pendokumentasian yang baik dan benar ditunjang oleh ketepatan kode diagnosis dan kode penyebab luar, dalam hal ini kode cedera dan kecelakaan lalu lintas harus seluruhnya akurat. (Hatta, 2013) Berdasarkan hasil studi pendahuluan yang dilaksanakan pada tanggal 4 Maret 2019 dengan mengambil 10 dokumen rekam medis kasus cedera kepala dan kecelakaan lalu lintas, didapatkan hasil akurasi untuk kode cedera kepala sebesar $20 \%$ atau 2 dari 10 dokumen rekam medis terkode akurat. Sementara untuk akurasi kode kecelakaan lalu lintas yaitu sebesar $0 \%$ atau 10 dokumen terkode tidak akurat. Ketidakakuratan kode paling banyak disebabkan karena tidak mencantumkan karakter kelima pada kode diagnosis dan tidak mencantumkan karakter keempat dan kelima pada kode penyebab luar.

\section{Metode}

Jenis penelitian kuantitatif deskriptif, populasi 145 dokumen rekam medis kasus cedera kepala yang disebabkan kecelakaan lalu lintas tahun 2018, total sampel 106. Teknik pengambilan sampel adalah simple random sampling. Cara pengumpulan data dilakukan dengan observasi. Analisis data yang digunakan analisis univariat 


\section{Hasil dan Pembahasan}

\section{a. Akurasi Kode Diagnosis Utama}

Tabel 1. Distribusi Frekuensi Akurasi Kode Diagnosis Kasus Cedera Kepala

\begin{tabular}{lcc}
\hline \multicolumn{1}{c}{$\begin{array}{c}\text { Keakuratan } \\
\text { Kode }\end{array}$} & f & $\%$ \\
\hline Akurat & 36 & 33,9 \\
Tidak Akurat & 70 & 66,1 \\
Jumlah & 106 & 100 \\
\hline
\end{tabular}

Sumber data: Data Primer Tahun 2018

Berdasarkan tabel 1, didapatkan bahwa tingkat akurasi kode diagnosis utama kasus cedera kepala sebagian besar tidak akurat dengan persentase sebesar 66,1\% dan 33,9\% akurat. Kode diagnosis utama kasus cedera kepala yang tidak akurat ditelaah dan diidentifikasi berdasarkan letak

ketidakakuratannya. Berikut adalah Identifikasi 70 kasus ketidakakuratan pada kode diagnosis utama berdasarkan letaknya:

Tabel 2. Identifikasi Letak Ketidakakuratan Pada Kode Diagnosis Utama Kasus Cedera

Kepala

\begin{tabular}{|c|c|}
\hline $\begin{array}{c}\text { Ketidakakuratan } \\
\text { Kode }\end{array}$ & $\mathrm{f}$ \\
\hline Tiga Karakter & 3 \\
\hline Karakter Keempat & 22 \\
\hline Karakter Kelima & 55 \\
\hline
\end{tabular}

Sumber data: Data Primer Tahun 2018

Seperti tampak pada tabel diatas, akurasi kode diagnosis utama kasus cedera kepala diuraikan berdasarkan letak ketidaktepatan kode, sebagai berikut:

1) Ketepatan tiga karakter yaitu ketepatan pada tiga karakter pertama yang merupakan kode yang sesuai dengan blok masing-masing pada ICD 10 terdiri atas satu huruf dan dua angka,
2) Karakter keempat yaitu satu karakter tambahan yang pada umumnya terdiri atas .0 - .9 yang di tulis dengan cara menambahkan titik kemudian angka setelah tiga karakter pertama, karakter keempat ini memberikan keterangan yang lebih spesifik pada kode tersebut seperti menunjukkan letak atau kondisi,

3) Karakter kelima. Penggunaan karakter kelima pada kodifikasi kasus cedera kepala dalam ICD-10 (S00-S09) digunakan untuk pemilihan jenis fraktur dan keterangan dengan/tanpa luka intrakranial terbuka. Karakter kelima untuk pemilihan jenis fraktur ini adalah sebagai berikut:

0 closed

1 open

Ketidakakuratan terbesar disebabkan oleh ketidakakuratan penggunaan karakter kelima dengan persentase sebesar 53,8 \% atau sebanyak 57 dokumen rekam medis. Penggunaan karakter kelima pada kodifikasi kasus cedera kepala dalam ICD-10 (S00-S09) digunakan untuk pemilihan jenis fraktur dan keterangan dengan/tanpa luka intrakranial terbuka. Karakter kelima untuk pemilihan jenis fraktur ini adalah sebagai berikut:

0 closed

1 open

Karakter kelima ini dikhususkan untuk kasus fraktur yaitu pada kategori S02 Fraktur pada tengkorak dan tulang wajah.

Karakter kelima untuk dan keterangan dengan/tanpa luka intrakranial terbuka adalah sebagai berikut:

0 without intracranial wound

1 with intracranial wound (WHO, 2010)

Pada penerapannya pemberian kode untuk karakter kelima ini sebagian besar tidak dituliskan. Pada ICD-10 disebutkan bahwa jika suatu diagnosis fraktur tidak ditetapkan jenis fraktur terbuka atau tertutup maka diklasifikasikan kedalam fraktur tertutup atau closed dan kode (.0) dapat ditambahkan sebagai karakter kelima, (WHO, 2010). Hal tersebut disebabkan karena di dalam beberapa 
dokumen rekam medis tidak terdapat keterangan luka/fraktur terbuka atau tertutup dan juga disebabkan oleh kurangnya ketelitian petugas kodifikasi dalam melihat jenis dari fraktur/luka tersebut. Selain itu, tidak adanya SPO yang mengharuskan kodifikasi untuk kode diagnosis kasus cedera kepala dikode sampai dengan karakter kelima membuat sebagian besar kode dikode sampai karakter keempat saja.

Ketidakakuratan kode diagnosis utama kasus cedera kepala sebagian besar disebabkan masih rendahnya penggunaaan karakter kelima, hal tersebut sejalan dengan penelitian yang dilakukan oleh Adinda Putri Amalia, dkk. Yaitu ketidakakuratan kode diagnosis cedera pada kasus kecelakaan lalu lintas sebagian besar disebabkan oleh penggunaan karakter kelima. (Amalia, Rosiati, dan Rumpiati., 2018)

b. Akurasi Kode penyebab luar Kasus Kecelakaan Lalu Lintas Berdasarkan ICD-10

Hasil penelitian terhadap 106 dokumen rekam medis rawat inap kasus cedera kepala yang disebabkan kecelakaan lalu lintas di RSUP Dr. Hasan Sadikin Bandung

tahun 2018. Berikut adalah hasil keakuratan kode untuk kode penyebab luar kasus kecelakaan lalu lintas:

Tabel 3. Distribusi Frekuensi Akurasi Kode penyebab luar Kasus Kecelakaan Lalu Lintas

\begin{tabular}{lcc}
\hline \multicolumn{1}{c}{$\begin{array}{c}\text { Keakuratan } \\
\text { Kode }\end{array}$} & $\mathrm{f}$ & $\%$ \\
\hline Akurat & 34 & 32,1 \\
Tidak Akurat & 72 & 67,9 \\
Jumlah & 106 & 100 \\
\hline
\end{tabular}

Sumber data: Data Primer Tahun 2018

Berdasarkan tabel 3 didapatkan bahwa tingkat akurasi kode penyebab luar kasus kecelakaan lalu lintas sebagian besar tidak akurat dengan persentase 67,9 \% dan $32,1 \%$ terkode akurat.

Kode penyebab luar kasus kecelakaan lalu lintas yang tidak akurat ditelaah dan diidentifikasi berdasarkan letak ketidakakuratannya. Berikut adalah identifikasi 72 kasus ketidakakuratan pada kode penyebab luar berdasarkan letaknya:

Tabel 4. Identifikasi Letak Ketidakakuratan Pada Kode penyebab luar

\begin{tabular}{lc}
\multicolumn{1}{c}{$\begin{array}{c}\text { Ketidakakuratan } \\
\text { Kode }\end{array}$} & $\mathrm{f}$ \\
\hline Tiga Karakter & 32 \\
Karakter Keempat & 36 \\
Karakter Kelima & 40
\end{tabular}

Sumber data: Data Primer Tahun 2018

Berdasakan hasil penelitian, akurasi kode penyebab luar kasus kecelakaan lalu lintas tahun 2018 didapatkan bahwa sebagian besar tidak akurat dengan presentasi sebesar $67,9 \%$ atau sebanyak 72 dokumen rekam medis.

Akurasi kode penyebab luar kasus kecelakaan lalu lintas diuraikan berdasarkan letak ketidaktepatan kode, dilihat dari ketepatan tiga karakter, karakter keempat dan karakter kelima. Penyebab ketidakakuratan terbanyak disebabkan oleh ketidakakuratan penggunaan karakter kelima.

Penggunaan karakter kelima dalam kode penyebab luar kasus kecelakaan lalu lintas digunakan untuk menunjukan aktivitas korban saat mengalami kecelakaan. Pada penerapannya, jika di dalam kronologi pasien masuk tidak disebutkan jenis aktivitas saat mengalami kecelakaan kode karakter kelima pun sebagian besar tidak dituliskan. Sebagaimana diketahui bahwa dengan tidak adanya keterangan aktivitas tersebut diidentifikasikan ke dalam aktivitas yang tidak ditentukan (.9) dan apabila mengacu pada aturan untuk bab XX ICD-10 kode tersebut harus dimasukkan. Hal tersebut 
disebabkan kurang telitinya petugas kodifikasi dalam membaca kronologi awal pasien. Tidak adanya SPO yang mengharuskan kodifikasi lengkap sampai karakter kelima pun bisa menjadi penyebab tidak terisinya karakter kelima pada kodifikasi kode penyebab luar kasus kecelakaan lalu lintas.

Ketidakakuratan kode penyebab luar kasus kecelakaan lalu lintas sebagian besar disebabkan ketidakakuratan penggunaaan karakter kelima sejalan dengan penelitian yang dilakukan oleh Carlina Mahardika Loka, dkk. yaitu ketidakakuratan kode diagnosiskasus cedera sebagian besar disebabkan oleh kesalahan atau ketidakakuratan tiga karakter, karakter kempat dan karakter kelima (Loka, dkk., 2012)

c. Identifikasi Penyebab Ketidakakuratan Kode Diagnosis dan Kode penyebab luar Kasus Cedera Kepala yang Disebabkan Kecelakaan Lalu Lintas

Berdasarkan hasil penelitian, identifikasi penyebab ketidakakuratan kode diagnosis dan kode penyebab luar kasus cedera kepala yang disebabkan kecelakaan lalu lintas adalah sebagai berikut:

1) Identifikasi Penyebab Ketidakakuratan Kode Diagnosis Utama

a) Ketidakakuratan Berdasarkan Tiga Karakter

b) Ketidakakuratan Berdasarkan Karakter Keempat

Karakter keempat untuk kode diagnosis utama kasus cedera kepala menunjukkan penentuan letak cedera kepala, dalam hal ini adalah letak dari fraktur, dislokasi, luka terbuka dan luka intracranial. Penyebab ketidakakuratan berdasarkan karakter keempat adalah ketidaktepatan dalam menentukan letak cedera.

c) Ketidakakuratan Berdasarkan Karakter Kelima

Karakter kelima untuk kode diagnosis utama kasus cedera kepala menunjukkan jenis dari fraktur (terbuka dan tertutup) dan dengan/tanpa luka intrakranial. Penyebab ketidakakuratan berdasarkan karakter kelima adalah tidak memberikan kode dan ketidaktepatan dalam menentukan jenis fraktur/luka terbuka atau tertutup.

Tiga karakter untuk kode diagnosis utama kasus cedera kepala menunjukkan jenis dari cedera kepala. Penyebab ketidakakuratan berdasarkan tiga karakter adalah ketidaktepatan dalam menentukan jenis cedera kepala.

Ketidakakuratan karakter kelima pada kode diagnosis utama kasus cedera kepala terletak pada ketidaktepatan dan tidak terisinya kode untuk pemilihan jenis fraktur

dan luka terbuka atau tertutup. Terdapat 55 kasus ketidakakuratan karakter keempat dengan kasus terbanyak yaitu terdapat pada 26 dokumen rekam medis diagnosis Concussion (S06.00) dengan kesalahan tidak

terisinya karakter kelima. Berikut adalah contoh dari ketidakakuratan karakter kelima:

“Diagnosis Utama Pada DRM :

Concussion

Kode Pada DRM : S06.0

ICD-10 Volume 1 : S06.0

Concussion

Kode Peneliti:

S06.00

ICD-10 Volume 1 : S06.0

Concussion

.0 without open intracranial "

Berdasarkan kasus tersebut, Diketahui bahwa diagnosis utama adalah Concussion artinya gegar pada kepala akan tetapi kode yang diberikan tidak akurat yaitu S06.2 yang merujuk pada ICD-1 volume 1 adalah kode untuk Concussion namun belum ditambahkan keterangan dengan/tanpa luka intrakranial. Peneliti melakukan kodifikasi ulang dan menghasilkan kode S06.00 yang merupakan kode untuk diagnosis Concussion. 
b) Identifikasi Penyebab Ketidakakuratan Kode penyebab luar

1) Ketidakakuratan Berdasarkan Tiga Karakter

Tiga karakter untuk kode penyebab luar kasus kecelakaan lalu lintas menunjukkan korban dan kendaraan yang digunakannsaat mengalami kecelakaan lalu lintas. Penyebab

ketidakakuratan kode penyebab luar berdasarkan tiga karakter adalah ketidaktepatan dalam menentukan jenis kecelakaan lalu lintas.

2) Ketidakakuratan Berdasarkan Karakter Keempat

Karakter keempat untuk kode penyebab luar kasus kecelakaan lalu lintas menunjukkan posisi korban saat mengalami kecelakaan lalu lintas yaitu sebagai pengendara atau penumpang. Berikut adalah penyebab ketidakakuratan kode penyebab luar berdasarkan karakter keempat:

- Ketidaktepatan dalam identifikasi kecelakaan lalu lintas dan non lalu lintas

- Ketidaktepatan dalam identifikasi korban yang mengalami kecelakaan

3) Ketidakakuratan Berdasarkan Karakter Kelima

Karakter kelima untuk kode penyebab luar kasus kecelakaan lalu lintas menunjukkan jenis aktivitas yang sedang dilakukan korban saat mengalami kecelakaan lalu lintas. Penyebab ketidakakuratan kode penyebab luar berdasarkan karakter kelima adalah tidak memberikan kode aktivitas yang sedang dialami oleh korban saat kejadian kecelakaan

Ketidakakuratan karakter kelima pada kode penyebab luar kasus kecelakaan lalu lintas terletak pada ketidaktepatan atau tidak terisinya pemilihan aktivitas korban saat mengalami kecelakaan. Terdapat 40 kasus ketidakakuratan penggunaan karakter kelima dengan kasus terbanyak adalah ketidakakuratan untuk 9 dokumen rekam medis kasus kecelakaan lalu lintas pengendara motor non tabrakan dan 6 dokumen rekam medis kasus kecelakaan lalu lintas pengendara motor tabrakan dengan sepeda motor lain. Berikut adalah contoh ketidakakuratan karakter kelima:

"Penyebab luar pada RM :

6 jam sebelum masuk rumah sakit, saat sedang mengedarai motor di daerah Cihanjuang, tiba-tiba bertabrakan dengan motor lain dari arah berlawanan sehingga pasien terjatuh dengan kepala membentur aspal

Kode Pada DRM : V23.4

ICD-10 Volume 1 : V23.4

Motorcycle rider injured in collision with car, pick-up truck or van [driver injured in traffic accident]

Kode Peneliti : V22.49

ICD-10 Volume 1 : V22.49

Motorcycle rider injured in collision with two- or three- wheeled motor vehicle [driver injured in traffic accident] [during unspecified activity]."

Berdasarkan kasus diatas, diketahui bahwa penyebab luar pada dokumen 6 jam sebelum masuk rumah sakit, saat sedang mengedarai motor di daerah Cihanjuang, tiba-tiba bertabrakan dengan motor lain dari arah berlawanan sehingga pasien terjatuh dengan kepala membentur aspal.

Kode yang tertera pada rekam medis adalah V23.4 yang merujuk pada ICD-10 volume 1 adalah kode untuk Motorcycle rider injured in collision with car, pickup truck or van [driver injured in traffic accident]

Pada kronologi tersebut tidak disebutkan jenis aktivitas yang dilakukan oleh korban. Setelah dilakukan kodifikasi ulang dihasilkan kode V22.49 dengan pemilihan tiga karakter V22 karena diketahui bahwa kecelakaan lalu lintas tersebut merupakan tabrakan antara sepeda motor dengan sepeda motor lainnya serta penambahan kode aktivitas yang tidak diketahui yaitu (.9). 


\section{Simpulan dan Saran}

Akurasi kode diagnosis dan kode penyebab luar kasus cedera kepala yang disebabkan oleh kecelakaan lalu lintas sebagian besar tidak akurat. ketidakakuratan kode diagnosis dan kode penyebab luar sebagian besar disebabkan oleh karakter kelima.

\section{Ucapan Terima Kasih}

Terima kasih disampaikan kepada Poltekkes Kemenkes Tasikmaya atas segala dukungan dalam proses penelitian dan tentunya praktisi PMIK di RSHS Bandung yang telah mendukung kepada pihak-pihak yang membantu pelaksanaan penelitian.

\section{Daftar Pustaka}

DPD PORMIKI. (2011), Materi Pelatihan Manajemen Rumah Sakit Dalam Menunjang Akreditasi dan Statistik Rumah Sakit dan Klasifikasi Penyakit. Yogyakarta: DPD PORMIKI.

Hatta, Gemala. (2013), Pedoman Manajemen Informasi Kesehatan di Sarana Pelayanan Kesehatan (edisi revisi 2). Jakarta: Penerbit Universitas Indonesia.

Herman dan Erma. (2018,) “Tinjauan Kelengkapan Diagnosis External Cause Pasien Rawat Inap" Jurnal Perekam Medis dan Informasi Kesehatan (JUPERMIK). 2(1) 54.

Ikhwan, Syamsuriansyah, dan Irawan (2016) “Tinjauan Ketepatan Kode Diagnosis Cedera Dan Penyebab Luar Cedera (External Causes) Pasien Rawat Inap Di Rumah Sakit Islam "Siti Hajar" Mataram" Jurnal Manajemen Informasi Kesehatan Indonesia 4(2).

KBBI (2019) Kamus Besar Bahasa Indonesia (KBBI). [Online] Available at: https://kbbi.web.id/akurasi, [Diakses 19 Feb 2019].
Kementerian Kesehatan RI. (2018), Laporan Nasional RISKESDAS 2018. Jakarta: Badan Penelitian dan Pengembangan Kemenkes RI.

Loka, Rano, dan M. Arief. (2013), “Tinjauan Keakuratan Kode Diagnosis Dan External Cause Pada Kasus Kecelakaan Lalu Lintas Pasien Rawat Inap Di Rumah Sakit Dr.Moewardi Periode Tahun 2012". Jurnal Rekam Medis. 7(1) 21-29.

Nazir. Moh. (2011), Metode Penelitian. Bogor: Ghalia Indonesia.

Ningsih, Ayu. (2016), Ketepatan Pengkodean Diagnosis Pada Kasus Cedera di RSUD Prambanan Tahun 2016 [Karya Tulis Ilmiah]. Yogyakarta: STIKES Jenderal Achmad Yani Yogyakarta.

Notoatmodjo, S. (2010), Metodologi Penelitian Kesehatan. Jakarta: Rineka Cipta.

Nurarif, A. H. dan Hardi Kusuma. (2015), Aplikasi Asuhan Keperawatan Berdasarkan Diagnosa Medis dan Nanda Nic-Noc Edisi Revisi Jilid 1. Yogyakarta: Mediaction Publishing.

Peraturan Menteri Kesehatan Republik Indonesia Nomor 269/MENKES/PER /III/2008 Tentang Rekam Medis Peraturan Menteri Kesehatan Republik Indonesia Nomor 1171/Menkes/PER/VI/2011

Tentang Sistem Informasi Rumah Sakit.

Pujihastuti dan Sudra. (2014), "HubunganKelengkapan Informasi Dengan Keakuratan Kode Diagnosis Dan Tindakan Pada Dokumen Rekam Medis Rawat Inap" Jurnal Manajemen Informasi Kesehatan Indonesia 3(1).

Ratmawati, Meida (2018), Tinjauan Akurasi Kode Diagnosis dan External Cause Pada Kasus Fraktur di RSUD Prof. Dr. Margono Soekarjo Purwokerto [Karya Tulis Ilmiah]. 
Tasikmalaya: Poltekkes Kemenkes Tasikmalaya.

Republik

Indonesia.

(1993)

PeraturanPemerintah Nomor 43

Tahun 1993 Pasal 93 Tentang Kecelakaan Lalu Lintas.

Republik Indonesia. (2004), Undang-Undang Nomor 29 Tahun 2004 Tentang Praktik Kedokteran

Republik Indonesia.

(2009),

Undang-Undang Nomor 44 Tahun 2009 Tentang Rumah Sakit.
Sugiyono. (2017), Metode Penelitian Kuantitatif, Kualitatif, dan R\&D. Bandung: Alfabeta.

Sujarweni, V. Wiratna. (2014), Metodologi Penelitian. Yogyakarta: Pustaka Baru Press.

WHO. (2010), International Statistical Classification of Diseases and Related Health Problems. Geneva: World Health Organizatiom. 